\title{
Failure of sheep-goat hybrid conceptuses to develop to term in sheep-goat chimaeras
}

\author{
R. A. Gustafson ${ }^{1}$, G. B. Anderson ${ }^{1 *}$, R. H. BonDurant ${ }^{2}$ and \\ G. R. Sasser ${ }^{3}$ \\ ${ }^{1}$ Department of Animal Science and ${ }^{2}$ Department of Reproduction, University of California, Davis, \\ CA 95616-8521 USA; and ${ }^{3}$ Department of Animal Science, University of Idaho, Moscow, ID 83843,
} USA

\begin{abstract}
Six hybrid pregnancies were established: three in sheep-goat chimaeras, one in a sheep(sheep-goat)hybrid chimaera and two in does. Pregnancies were monitored weekly by ultrasonography and peripheral concentrations of pregnancy specific protein B (PSPB) were measured. Placental development as detected by ultrasonography appeared to be slower in hybrid-in-goat pregnancies than in hybrid-in-chimaera pregnancies, although this difference was not reflected in PSPB concentrations. Time of fetal death could not be predicted from PSPB concentrations. Chimaeras appeared to carry hybrid pregnancies longer than ewes and does usually carry hybrid pregnancies, but none was carried to term.
\end{abstract}

\section{Introduction}

The domestic sheep, Ovis aries, and domestic goat, Capra hircus, do not normally interbreed. Ewes usually will not conceive when bred to a buck. Through the use of artificial insemination and embryo transfer, hybrid pregnancies have been established in ewes, but they are lost by 4-6 weeks of gestation (Hancock et al., 1968; MacLaren et al., in press). Does will conceive when mated to a ram, but pregnancy is usually lost by 8 weeks of gestation (Warwick and Berry, 1949; Hancock et al., 1968; Hancock and McGovern, 1968; McGovern, 1973a; MacLaren et al., in press). Occasional sheep-goat hybrids born to does have been reported (Bunch et al., 1976; Moore et al., 1981; Tucker et al., 1989). Dent et al. (1971) proposed that loss of hybrid-in-goat pregnancies can be attributed to placental failure, possibly due to a maternal immune response (Hancock et al, 1968). Sheep-goat chimaeras provide a useful model to test this theory because they are immunologically tolerant to both component lines (MacLaren et al., 1992b; Gustafson et al., 1993). If failure of hybrid-in-goat pregnancies is due to an immune response, the sheep-goat chimaera should be capable of carrying sheep, goat and hybrid pregnancies, but this is not the case. Eight female sheep-goat chimaeras were shown to carry lambs to term, but goat pregnancies were lost from day 23 to some time after day 40 (MacLaren et al., 1992a, b). Establishment of hybrid pregnancies in sheep-goat chimaeras was attempted by Fehilly and Willadsen (1986); however, none developed to term and it is unclear whether pregnancy was ever established.

If placental function is compromised in interspecific and hybrid pregnancies, production of placental products would be expected to be affected. Such an effect has been observed with mares carrying mule conceptuses where greatly reduced concentrations of equine chorionic gonadotrophin (eCG) are

${ }^{*}$ Correspondence and reprint requests.

Revised manuscript received 13 May 1993. measured (Allen, 1975). Pregnancy specific protein B (PSPB) has been identified in maternal circulation during pregnancy in ruminants, including cattle (Butler et al., 1982), sheep (Ruder et al., 1988), goats (Humblot et al., 1990) and deer (Wood et al., 1986). PSPB is localized in (Eckblad et al., 1985) and secreted (Reimers et al., 1985) from the binucleate cells of the trophoblastic ectoderm. The biological function(s) of PSPB has not been determined but has been linked to immunosuppression (Dunbar et al., 1990).

This study was undertaken to determine the outcome of hybrid pregnancies in sheep-goat chimaeras, using secretion of PSPB and ultrasonography to monitor pregnancy.

\section{Materials and Methods}

\section{Animals}

Establishment of hybrid pregnancies was attempted in six female sheep-goat chimaeras produced in previous experiments (Roth et al., 1989; Ruffing, 1989), a sheep-(sheep-goat)hybrid chimaera (Roth et al., 1989), two Finn ewes and two Alpine does. The chimaeras had previously resorbed caprine and carried to term ovine pregnancies (MacLaren et al., 1992a, b). Hybrid embryo donors consisted of one multiparous and five virgin Alpine does. Intraspecific pregnancies were obtained by mating three white-face ewes and an Alpine doe to a fertile ram and buck, respectively.

\section{Synchronization, insemination and embryo transfer}

All animals were synchronized by use of intravaginal pessaries containing $40 \mathrm{mg}$ fluorogestone acetate (Chrono-gest: Intervet, Boxmeer) inserted for 10 days. Lutalyse $(15 \mathrm{mg}$; Upjohn, Kalamazoo, MI) was administered at the time of pessary removal. Does used as hybrid embryo donors were 
superovulated with twice daily injections of FSH (FSH-P: Shering, Kenilworth, NJ) in decreasing doses of 5.5, 4.4 and $3.3 \mathrm{mg}$, respectively, for 3 days beginning the day before pessary removal.

Insemination of the donor does with $150-200 \times 10^{6}$ motile ovine spermatozoa was performed by laparoscopy to one uterine horn near the bifurcation 50-54 h after pessary removal. For this procedure, does were sedated with diazepam $(0.15 \mathrm{mg}$ $\mathrm{kg}^{-1}$, i.v.: Schein, Port Washington, NY) and the skin and abdominal wall were anaesthetized by local infiltration of lidocaine (Elkins-Sinn, Inc., Cherry Hill, NJ). Semen was collected by electroejaculation and centrifuged for $20 \mathrm{~min}$ at $300 \mathrm{~g}$ over a discontinuous Percoll (Sigma, St Louis, MO) gradient consisting of $2 \mathrm{ml}$ decreasing concentrations of $70 \%, 50 \%$ and $40 \%$ Percoll solution diluted in $1 \times$ basal medium (BM). The Percoll solution consisted of 9:1 Percoll:10 $\times$ basal medium (10 $\times$ BM: $1.13 \mathrm{~mol}$ $\mathrm{NaCll}^{-1}, 0.03 \mathrm{~mol} \mathrm{KCll}^{-1}, 0.2 \mathrm{~mol} \mathrm{Tris} l^{-1}, 0.1$ mol glucose $^{-1}$, $0.05 \mathrm{~mol}$ sodium pyruvate $\mathrm{I}^{-1}, 0.1 \mathrm{~mol} \mathrm{CaCl} \mathrm{l}^{-1}, 500 \mathrm{iu}$ penicillin $\mathrm{G} \mathrm{ml}^{-1}, 0.5 \mathrm{ng}$ streptomycin sulfate $\mathrm{ml}^{-1}$ ). The sperm pellet was then washed twice with $1 \times \mathrm{BM}$ and the final suspension held at $37^{\circ} \mathrm{C}$ in $1 \times \mathrm{BM}$ supplemented with $0.5 \% \mathrm{BSA}$ (Sigma) until use.

Morula- to early blastocyst-stage hybrid embryos were collected at laparotomy 5 days after insemination according to methods described by Anderson et al. (1981). Embryos were held in culture in Whitten's medium (Whitten and Biggers, 1968) supplemented with $0.5 \%$ BSA and $1 \%(\mathrm{v} / \mathrm{v})$ antibioticantimycotic solution (100 X, Gibco, Grand Island, NY) under dimethyl-polysiloxane (Sigma, St Louis, MO) at $37^{\circ} \mathrm{C}$ in $5 \%$ $\mathrm{CO}_{2}$ until transfer to recipients. Ovulation in the recipients (chimaeras and ewes) was confirmed at laparotomy and one to three embryos were transferred to a uterine horn ipsilateral to a corpus luteum. Hybrid pregnancies in does were established by natural mating to a Barbados ram.

\section{Pregnancy detection and monitoring}

Animals were observed daily for return to oestrus. Chimaeras were housed with a vasectomized ram wearing a marking harness from day 15 onwards. Ewes and chimaeras that returned to oestrus were bred naturally to rams to establish intraspecific and ovine pregnancies, respectively. Animals that did not show signs of oestrus by day 26 (first day of oestrus $=$ day 0 ) were examined by real-time ultrasonography using a $3.5 \mathrm{MHz}$ transabdominal probe twice weekly, first for pregnancy detection and then monitoring, until pregnancy was lost or to within 3-4 weeks of parturition.

Blood samples were collected daily from days 18 to 32 , every other day from days 34 to 60 , twice weekly from days 62 to 89 and once weekly from day 90 until $2-3$ weeks after parturition (or 1-2 weeks after pregnancy loss). Blood was collected by jugular venepuncture into $10 \mathrm{ml}$ vacutainer tubes (BectonDickenson, Rutherford, NJ), allowed to coagulate at room temperature and centrifuged at $2500 \mathrm{~g}$ for $10 \mathrm{~min}$. The serum was collected and stored at $-20^{\circ} \mathrm{C}$ until analysis for PSPB.

\section{Radioimmunoassay}

Serum samples were analysed for PSPB in two radioimmunoassays as described by Willard et al. (1987). Rabbit anti-
Table 1. Results of hybrid embryo transfer to sheep-goat chimaeras and to ewes

\begin{tabular}{|c|c|c|c|}
\hline Animal & $\begin{array}{l}\text { Embryos } \\
\text { transferred }\end{array}$ & Outcome & $\begin{array}{l}\text { Pregnancy } \\
\text { termination }\end{array}$ \\
\hline $8702-S H C$ & $\begin{array}{l}\text { I blastocyst } \\
\text { I morula } \\
\text { I 16-cell }\end{array}$ & Pregnant & $<$ Day 125 \\
\hline $8703-C$ & 2 morulae & Not pregnant & 一 \\
\hline $8704-C$ & I morula & Not pregnant & - \\
\hline $8806-C$ & 2 blastocysts & Pregnant & $<$ Day 89 \\
\hline $8809-C$ & 3 morulae & Pregnant & $<$ Day 70 \\
\hline $8810-C$ & $\begin{array}{l}\text { I blastocyst } \\
\text { I morula }\end{array}$ & delayed oestrus ${ }^{b}$ & - \\
\hline $8811-C$ & 2 morulae & Pregnant & $<$ Day 49 \\
\hline $102-S$ & 1 blastocyst & Not pregnant & - \\
\hline $103-S$ & 2 morulae & Not pregnant & - \\
\hline
\end{tabular}

${ }^{2}$ Day ultrasonography revealed a nonviable fetus or nonpregnant state. bDelayed return to oestrus, stood to be mounted by a ram on day 46. SHC: sheep-hybrid chimaera; C: sheep-goat chimaera; S: sheep.

serum to sheep PSPB was used with bovine PSPB (laboratory preparation $\mathrm{R}-37$ ) as the labelled standard protein. The mean sensitivity of the standard curve for two assays, expressed as two standard deviations from buffer control, was $156.2 \mathrm{pg}$ per assay tube (sample size was $200 \mu \mathrm{l}$ per tube). Inter- and intraassay coefficients of variation were 8.05 and $5.92 \%$, respectively. Serial dilutions (with virgin ewe serum) of pooled serum of hybrid-in-goat and hybrid-in-chimaera pregnancies inhibited binding of radiolabelled $\left({ }^{125} \mathrm{I}\right)$ bovine PSPB in a manner parallel to the standard curve. Serum samples from intraspecific ovine and caprine pregnancies were previously tested (Willard et al., 1987) and also inhibited binding parallel to the standard curve.

\section{Statistical analysis}

PSPB data were subjected to analysis of covariance using the SAS General Linear Models procedure (SAS, 1985). PSPB concentrations (absolute values and increases above basal concentrations analysed separately) were used as the dependent variable and type of pregnancy (for example, sheep-in-sheep, hybrid-in-chimaera) and day of pregnancy were independent variables with day of pregnancy used as a covariance. PSPB concentrations for the different types of pregnancy were compared at day 24 using an unpaired $t$ test. Day-24 PSBS concentrations were compared because differences resulting from different numbers of conceptuses are not detectable at this time (Humblot et al., 1990).

\section{Results}

\section{Embryo transfer}

Five early blastocysts, 12 morulae, one 16-cell and four degenerating hybrid embryos were recovered from six donor does. Embryos were transferred to a total of seven chimaeras and two virgin ewes (Table 1). 
Table 2. Results of natural matings of sheep-goat chimaeras, ewes and does

\begin{tabular}{|c|c|c|c|}
\hline Animal & Bred to & Outcome & $\begin{array}{l}\text { Pregnancy } \\
\text { termination }\end{array}$ \\
\hline $8703-\mathrm{C}$ & Ram & Pregnant & Day 145 , triplet lambs ${ }^{2}$ \\
\hline $8704-C$ & Ram & Pregnant & Day 143 , single lamb $b^{a, b}$ \\
\hline $102-S$ & Ram & Pregnant & Day 143 , single lamb \\
\hline $103-S$ & Ram & Pregnant & Day 146, twin lambs \\
\hline $204-S$ & Ram & Pregnant & Day 145 , single lamb \\
\hline $25-G$ & Ram & Pregnant $^{c}$ & $<$ Day $54^{\mathrm{d}}$ \\
\hline $4083-G$ & Ram & Pregnant & $<$ Day $40^{\text {d }}$ \\
\hline $30-G$ & Buck & Pregnant & Day 149 , quadruplet kids \\
\hline
\end{tabular}

aSpecies determined by phenotype at birth. 'Delivered by Caesarian section. 'After the first breeding, doe returned to oestrus 7 days later and was rebred. Conception was assumed to have occurred at the second breeding. ${ }^{\mathrm{d} D a y}$ ultrasonography revealed a nonviable fetus. C: sheep-goat chimaera; S: sheep; G: goat.

Hybrid embryo transfer pregnancies were conclusively established in four of seven chimaeras. Two of the remaining three chimaeras, 8703 and 8704 , returned to oestrus on day 16 , were bred naturally to a ram and conceived. The other chimaera, 8810 , had a delayed return to oestrus and stood to be mounted by a vasectomized ram wearing a marking harness on day 46 . Of the two ewes that received hybrid embryos, both returned to oestrus on day 16 , were bred naturally to a ram and conceived. Both does that were bred to a ram conceived, and the one doe bred to a buck also conceived. Results of natural matings are summarized (Table 2).

\section{Ultrasonography}

Hybrid-in-chimaera. In the five chimaeras that received hybrid embryos and did not return to oestrus, ultrasonography revealed a fluid-filled uterus in three on day 26 and four on day 29. The fifth chimaera, 8810 , returned to oestrus on day 46 and at no time before that did ultrasonography reveal signs of pregnancy. On day 31 in 8809 and 8811 , the uterine wall appeared irregular and by day 40 placentome formation in all four chimaeras was evident as projections along the uterine wall (Fig. Ia). As pregnancy progressed, the number and size of the placentomes increased and they became more c-shaped (Fig. Ib, c). The fetus was not always evident, but heartbeats were first detected on day 35 and were used to determine the viability of the fetus. In two cases, 8702 and 8806 , in which pregnancy progressed the furthest, fetal movement was used to indicate viability when the heartbeat could no longer be easily detected.

Chimaera 8811 was the first to resorb the hybrid pregnancy. On day 40 , pregnancy was evident in the form of a fluid-filled uterus and placentome formation, but by day 49 all signs of pregnancy had disappeared. The fetus was never observed directly during the course of this pregnancy. The last sign of a viable fetus in 8809 was a heartbeat on day 40 . The fetus was next seen on day 52 , but neither a heartbeat nor movement was detected. Signs of resorption appeared on day 70 ; the (a)

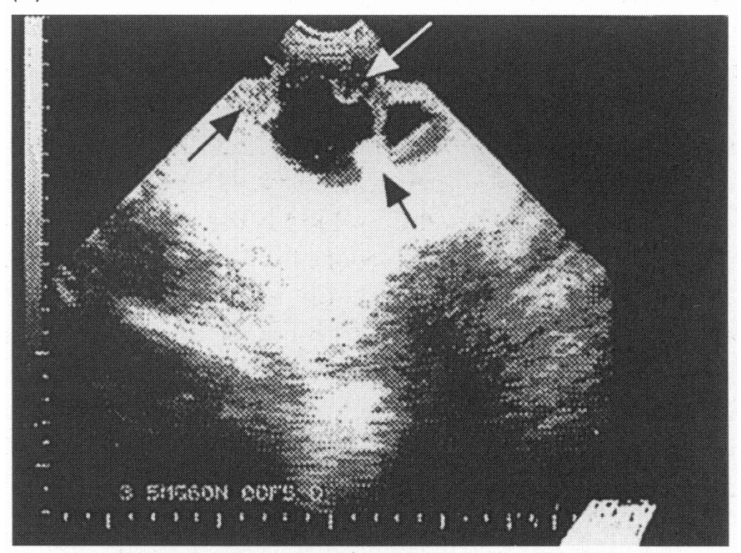

(b)

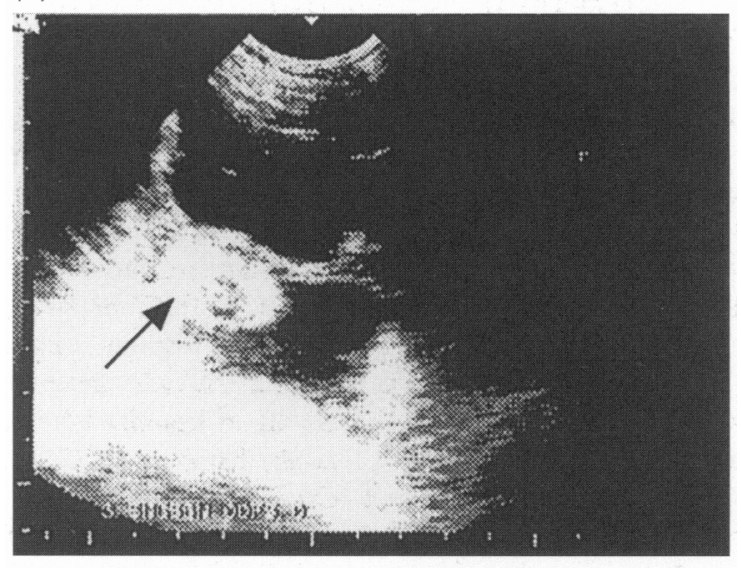

(c)

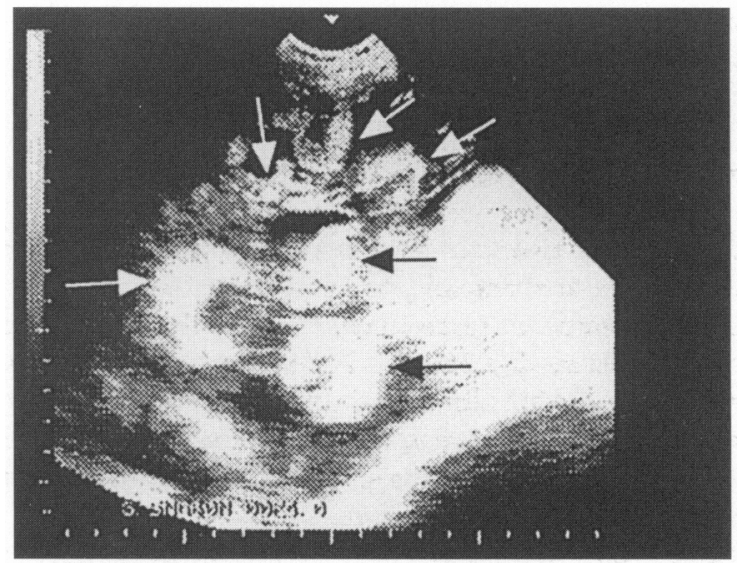

Fig. 1. Transabdominal ultrasonogram of (a) hybrid pregnancy in chimaera 8809 at day 40 , (b) hybrid pregnancy in chimaera 8702 at day 52 , and (c) sheep pregnancy in chimaera 8703 at day 58. Arrows indicate placentome formation. In (a) placentomes appear as projections into the central lumen; (b) demonstrates development of placentomes as ' $c$ ' or ' $O$ ' shaped structures and in (c) numerous well-developed placentomes are evident.

placentomes were smaller, there was less fluid and it was cloudier than observed previously. Continued loss of fluid and shrinking placentomes persisted until day 104, when pregnancy was no longer apparent. 


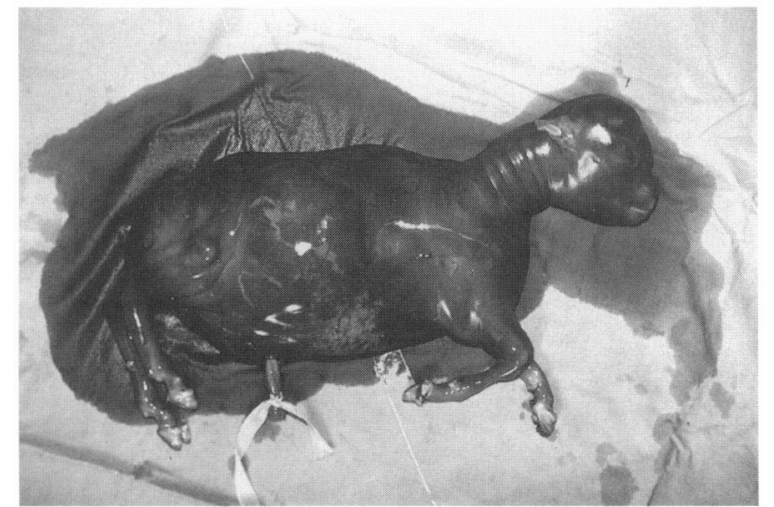

Fig. 2. Hybrid fetus obtained by Caesarian section from chimaera 8702 on day 126 . The fetus weighed $1.53 \mathrm{~kg}$ upon removal and had a crown-rump length of $32 \mathrm{~cm}$.

Chimaera 8806 had a live fetus on day 70 . On day 89 the fetus was observed, but no movement was detected. The female was marked by a vasectomized ram wearing a marking harness on day 99 and on day 104 no signs of pregnancy were detected with ultrasonography.

The hybrid pregnancy in the sheep-hybrid chimaera, 8702 , was carried the longest. Fetal movement was last detected on day 89. By day 104 the amount of fluid had increased dramatically, leading to a diagnosis of a possible hydroamnious condition. The abdominal measurements of the chimaera were taken twice weekly and started to decrease at about day 120 . Since ultrasonography on day 125 revealed neither fetal heartbeat nor movement, the fetus was removed by Caesarian section on day 126. Both the fetus and placenta were necrotic and judged to have been dead for about 5 days. The fetus had bulldog features to its face and its abdomen was distended with fluid. It weighed $1.53 \mathrm{~kg}$ and had a crown-rump length of $32 \mathrm{~cm}$ (Fig. 2). The allantochorion contained 55-57 cotyledons. In a previous term ovine pregnancy, placental membranes from this female contained 73 cotyledons (MacLaren et al., 1992a).

Hybrid-in-goat. A fluid-filled uterus was first detected in doe 4038 on day 33 . By day 39 a fetal heartbeat, the beginnings of placentome formation and excessive accumulation of placental fluid were observed. On day 40 a fetal heartbeat could no longer be detected and observations on day 46 and 49 revealed that the uterine contents were shrinking and becoming increasingly dense. Pregnancy was no longer detectable on day 51 .

Doe 25 was bred to a ram and then rebred 7 days later owing to a short oestrous cycle. It was assumed that conception occurred at the second breeding. Pregnancy was first detected on day 27 and a heartbeat on day 41. Placental development did not progress beyond irregularities along the uterine wall, first detected on day 41. Last signs of fetal viability were observed on day 44 . The fetus was detected on days 50 and 57 , but no heartbeat or movement was observed and all signs of pregnancy disappeared by day 62 . Excessive accumulation of placental fluids was not apparent.

Sheep-in-chimaera. Pregnancy was first detected in chimaeras 8703 and 8704 on day 26 by using a $5 \mathrm{MHz}$ linear probe inserted into the rectum during ultrasonography. In many animals this approach was not successful because the uterus was beyond the range of the probe, although occasional membranes could be seen if the abdominal area was manually elevated.

In both chimaeras carrying ovine pregnancies, fetal heartbeat, fetal movement and c-shaped placentomes were seen by day 39 and the placentomes continued to develop in size. Both pregnancies resulted in term lambs; 8703 had triplets by natural delivery on day 145 and 8704 had a single lamb by Caesarian section after failure of the cervix to dilate during labour on day 143.

Sheep-in-sheep and goat-in-goat. In intraspecific ovine pregnancies, ultrasonography revealed an irregular uterine wall, fetuses and fetal heartbeat on days 30-33. The placentomes continued to develop and had an obvious c-shape by day 42 . Ewes 204 and 102 delivered single lambs on day 145 and 143 , respectively, and ewe 103 delivered twin lambs on day 146 .

In the intraspecific caprine pregnancy an irregular uterine wall was first detected on day 37 and the c-shape to the placentomes became apparent at about day 40 with obvious placentation by day 51 . Doe 30 gave birth to quadruplets on day 149 .

\section{Pregnancy specific protein $B$}

Hybrid-in-chimaera. The three hybrid pregnancies in sheepgoat chimaeras $(8806,8809$ and 8811$)$ had lower concentrations of PSPB than did the hybrid pregnancy in the sheep-hybrid chimaera (8702, Fig. 3). One chimaera, 8810, with delayed return to oestrus had very low concentrations $\left(<1.9 \mathrm{ng} \mathrm{ml}^{-1}\right)$ of PSPB indicating non-pregnancy or very early pregnancy failure. All four confirmed hybrid pregnancies showed the same rate of increase in PSPB concentrations up to day 30, after which there was individual variation. In three animals (8702, 8809 and 8811 ), the decline of PSPB occurred at the estimated time of fetal death. In contrast, chimaera 8806 had an increase in PSPB concentration at the estimated time of fetal death.

Hybrid-in-goat. The concentrations of PSPB in the two hybrid-in-goat pregnancies varied greatly (Fig. 4a). Doe 4038 had higher concentrations than did doe 25 up to day 32 and then the concentrations in doe 25 increased beyond those of 4038. In the pregnancy of doe 25, PSPB concentrations declined at the estimated time of fetal death. In 4038 the decline occurred before fetal death and there was a slight increase after the pregnancy was resorbed and no longer detectable by ultrasonography. This increase was also seen in chimaera 8806 .

Sheep-in-chimaera. Chimaeras 8703 and 8704 had unusually high basal concentrations (day 0) of PSPB, 19.52 and $8.27 \mathrm{ng}$ $\mathrm{ml}^{-1}$, respectively. Both animals had increased concentrations of PSPB until approximately day 60 and then concentrations declined. In 8703, PSPB began to rise again at about day 105 but in 8704 concentrations remained low (Fig. 4b).

Sheep-in-sheep and goat-in-goat. The profile of PSPB in intraspecific ovine pregnancies showed two peaks, although the timing of these peaks varied among individuals (Fig. 4c). In two 


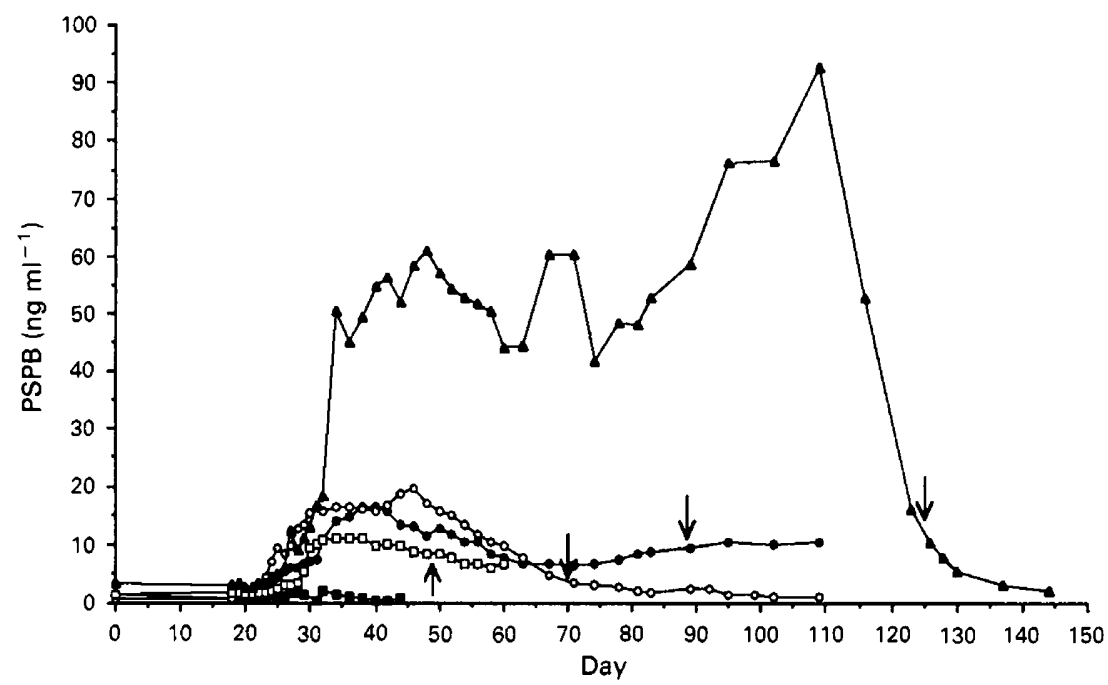

Fig. 3. Pregnancy specific protein B (PSPB) concentrations in peripheral blood of hybridin-chimaera pregnancies. Arrows indicate when a nonviable fetus or nonpregnant state was detected by ultrasonography. Chimaera 8810 was not confirmed pregnant. Values for

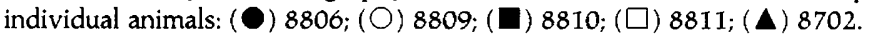
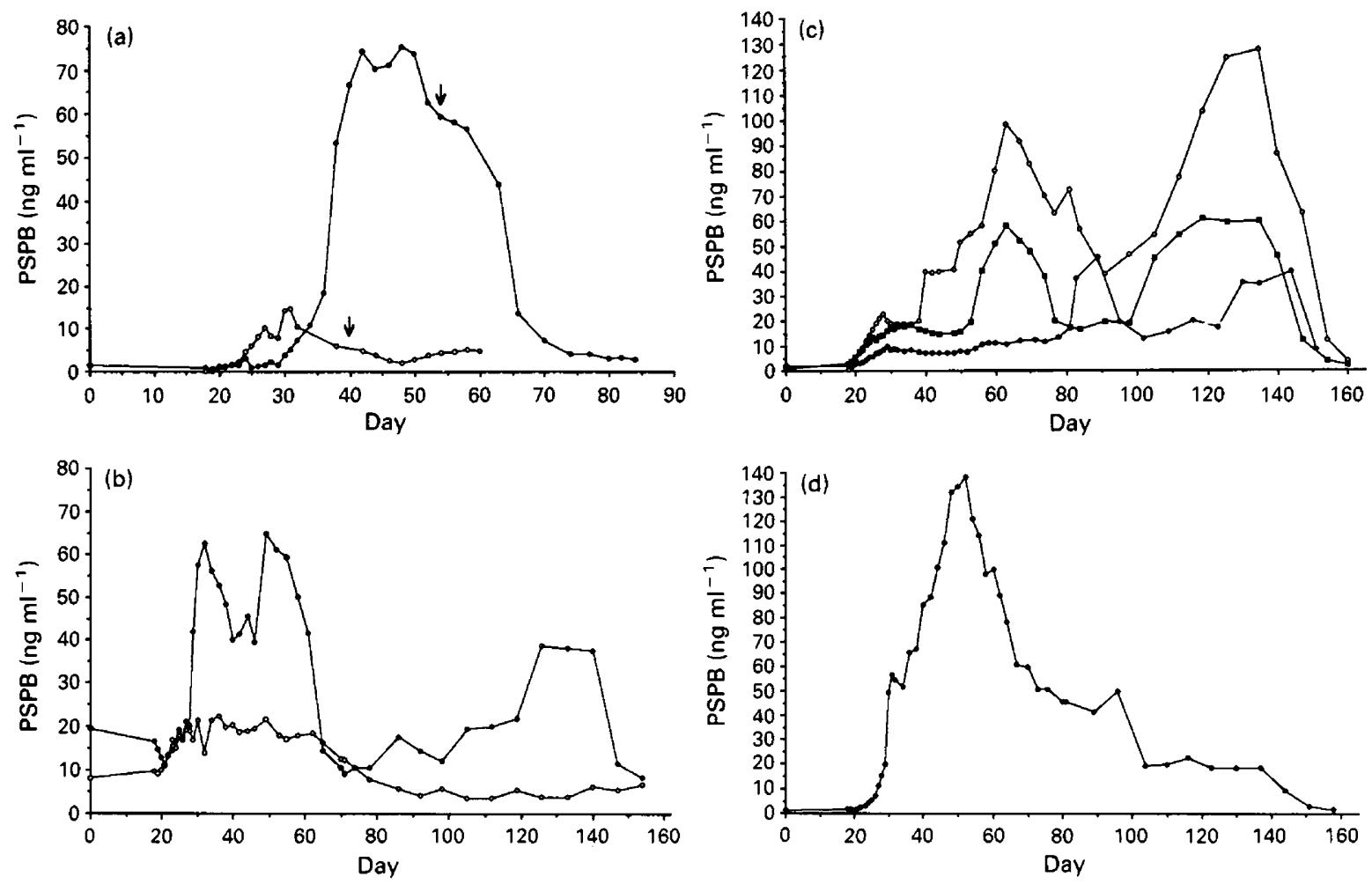

Fig. 4. Pregnancy specific protein B (PSPB) concentrations in peripheral blood of (a) hybrid-in-goat, (O) 25, (O) 4038; (b) sheep-inchimaera, (O) 8703, (O) 8704; (c) sheep-in-sheep, (O) 204, (O) 102, (⿴) 103; and (d) goat-in-goat pregnancies. Arrows in (a) indicate when a nonviable fetus was detected by ultrasonography.

animals, ewes 102 and 103, the first and second peaks occurred at approximately day 60 and day 130 , respectively. In the third animal, ewe 204, the peaks occurred at approximately day 90 and day 145. The PSPB profile from the goat-in-goat pregnancy had a single peak at approximately day 60 and then steadily declined (Fig. 4d).
Overall. The rate of change of PSPB from days $18-30$ did not differ among animals (slope $=0.4501, P>0.05$ ). Absolute concentrations of PSPB $(P<0.0001)$, but not increases above basal concentrations $(P>0.05)$, were different for the different types of pregnancies. Females carrying ovine pregnancies $(n=$ 5) had higher absolute concentrations of PSPB at day 24 than 
Table 3. Summary of mean pregnancy specific protein B (PSPB) concentrations at day 24

\begin{tabular}{lccr} 
Type of pregnancy & $\begin{array}{c}\text { Number of } \\
\text { animais }\end{array}$ & PSPB $\left(\mathrm{ng} \mathrm{ml}^{-1}\right)$ \\
\hline Ovine conceptuses & 5 & $12.69 \pm 1.86^{\mathrm{a}}$ \\
Sheep-in-sheep & 3 & & $10.61 \pm 2.44$ \\
Sheep-in-chimaera & 2 & & $15.81 \pm 0.70^{\mathrm{a}}$ \\
Hybrid conceptuses & 6 & $4.13 \pm 0.68^{\mathrm{a}}$ & \\
Hybrid-in-goat & 2 & & $3.99 \pm 0.86$ \\
Hybrid-in-chimaera & 4 & & $4.20 \pm 1.01^{\mathrm{a}}$ \\
Goat-in-goat & 1 & 4.45 & \\
\hline
\end{tabular}

Values are means \pm SEM.

"Within a column, values with superscripts were significantly different $(P<0.025)$.

did those carrying hybrid pregnancies $(n=6)$, regardless of the maternal species $(P<0.025)$ (Table 3$)$. Sheep-in-chimaera pregnancies $(n=2)$ had higher PSPB concentrations than did hybrid-in-chimaera pregnancies $(n=4)(P<0.025)$. PSPB concentrations were not different in sheep-in-sheep $(n=3)$ versus sheep-in-chimaera and hybrid-in-goat $(n=2)$ versus hybrid-inchimaera pregnancies $(P>0.05)$. When PSPB concentrations on day 24 were corrected for basal values, concentrations in sheep-in-chimaera pregnancies were higher than those for hybrid-in-chimaera pregnancies $(P<0.05)$. PSPB concentrations after 30 days were highly variable and no relationships between maternal species, type of pregnancy and concentration of PSPB were observed $(P>0.05)$.

\section{Discussion}

PSPB profiles of goat-in-goat pregnancies show a steady rise reaching peak values at approximately day 121 with a sharp decline after parturition (Humblot et al, 1990). The concentration of PSPB in the goat-in-goat pregnancy in this study reached a peak at approximately day 60 and then declined. However, the concentrations of PSPB were comparable to those of does carrying multiple conceptuses in the study of Humblot et al. (1990). The PSPB profile of ewes is different from that of does, showing two peaks at approximately day 60 and day 120 (Willard, 1991). Results from our sheep-in-sheep pregnancies were consistent with this report.

Hybrid pregnancies had lower concentrations of PSPB on day 24 than did ovine pregnancies. High basal PSPB concentrations in chimaeras that carried ovine pregnancies raise a possibility that comparisons were influenced by unusually high concentrations during pregnancy in these two females. The reason for the high basal concentrations is unknown. The PSPB antibody used in the radioimmunoassay crossreacts with ovine $\mathrm{LH}$, prolactin, growth hormone and thyroid-stimulating hormone in quantities greater than $1 \mu \mathrm{g}$ per tube (Willard et al., 1987), but crossreactivity would not be expected to affect analysis of sera from only two animals in the study. Low concentrations of PSPB could be due to the smaller size of hybrid embryos and fetuses compared with sheep or goat fetuses at the same stage (Warwick and Berry, 1949; Hancock and McGovern,
1968; Roth et al., 1989), indicating slower growth. However, concentrations of PSPB in the hybrid pregnancies were comparable to concentrations of PSPB in the one goat-in-goat pregnancy established during this study.

Placental formation, observed by ultrasonography, did not appear retarded in the hybrid-in-chimaera pregnancies when compared with sheep-in-sheep, sheep-in-chimaera and goat-ingoat pregnancies. Hybrid-in-goat pregnancies appeared to have less developed placentomes at the same stage (days 40-57) than those seen in hybrid-in-chimaera, sheep-in-chimaera, sheep-in-sheep and goat-in-goat pregnancies, and never progressed beyond small projections along the uterine wall. These findings are consistent with those of Hancock and McGovern (1970), who observed that the placenta in hybrid-in-goat pregnancies failed to establish normal contact and placentomes were underdeveloped; however, there were also pregnancies in which placentomes were normal in size but necrotic changes had taken place. McGovern (1973b) reported similar observations: cotyledons were in some cases inconspicuous and in other cases well developed but abnormal in appearance.

In one hybrid-in-goat pregnancy, doe 25, PSPB concentrations were exceptionally high, comparable to those of intraspecific caprine pregnancies with multiple conceptuses (Humblot et al., 1990), although the presence of more than one conceptus was never confirmed by ultrasonography. The PSPB concentrations in this goat were also comparable to those of chimaera 8702 , the sheep-hybrid chimaera that carried the hybrid pregnancy furthest in gestation. This observation suggests that concentrations of PSPB are not useful for predicting the health and longevity of an interspecies pregnancy.

Does lose second hybrid pregnancies earlier in gestation than they do the first (Bowerman and Hancock, 1963; McGovern, 1973a; MacLaren et al., 1992b), suggesting involvement of immune response in fetal death. Although sheep-goat chimaeras are tolerant to ovine and caprine species-specific antigens (MacLaren et al., 1992b; Gustafson et al., 1993), hybrid pregnancies were still lost. Loss occurred later in gestation than with sheep and goats carrying hybrid pregnancies, suggesting that they resulted from faulty fetal-maternal interactions. The sheep-hybrid chimaera carried the hybrid pregnancy the longest and had high PSPB concentrations with a profile similar to that of a sheep-in-sheep pregnancy. The presence of hybrid tissue in this animal may have contributed to appropriate fetalmaternal interactions that allowed the pregnancy to be carried for this long. The facial defects of the fetus suggest that the cause of pregnancy failure was a developmental problem. It is unlikely that these deformities occurred because the fetus was a hybrid; normal-looking hybrids have been recovered from hybrid-in-goat pregnancies (Warwick and Berry, 1949) and occasional hybrids have developed to term (Bunch et al, 1976; Moore et al., 1981; Tucker et al,, 1989). The genus Ovis has a number of chromosomes varying from 54 to 58 (Nadler $e$ al al, 1971); it is therefore believed that the chromosome number intermediate to the parental species of the hybrid is not responsible for its death in utero. Unexplained cranial defects and hydranencephaly have been reported in Dall's sheep-indomestic sheep pregnancies (Buckerell et al., 1990). There was no evidence of hydranencephaly in the hybrid fetus recovered in the case reported here and histological examination did not reveal pathological organisms. 
Chimaera 8703 had a PSPB profile that could be considered similar to a sheep-in-sheep profile because there were two corresponding peaks at the appropriate times, but there was also a third peak (day 31) earlier than the first in sheep (day 60). Chimaera 8704 had a PSPB profile that rose, levelled off and then declined by day 80 and remained low throughout gestation. These two different profiles for the same type of pregnancy (sheep-in-chimaera) could indicate influence of the maternal environment on the function of the binucleate cells (the uterine chimaerism of these animals was unknown). Placental hormone production may have been unusual in this animal as her cervix failed to dilate during labour. Combined with the unusual PSPB profile (reported here), progesterone profiles and placentas in other chimaeras (MacLaren et al., 1992a), maternal chimaerism appears to affect placental formation and function.

In summary, ultrasonography revealed that gross placental development appeared more normal in hybrid-in-chimaera than in hybrid-in-goat pregnancies, although this difference was not reflected in PSPB concentrations. From days 18 to 30 , hybrid pregnancies had lower peripheral concentrations of PSPB than did ovine pregnancies. If this difference is real, it could be a reflection of the smaller and possibly more slowly developing hybrid fetus or compromised fetal-maternal interactions affecting function of the binucleate cells. A decline in PSPB concentrations was not clearly indicative of fetal death. The chimaeras carried hybrid pregnancies longer than did sheep and also for longer than goats usually carry second hybrid pregnancies. Two chimaeras carried hybrid pregnancies longer than goats usually carry first hybrid pregnancies, despite failure of previous caprine pregnancies and consequent exposure to caprine antigens. None of the hybrid pregnancies was carried to term.

The authors thank B. Alexander, S. Donahue, A. Moyer and J. Rowe for assistance with various aspects of this project and C. Mahi-Brown and D. Bernoco for helpful criticisms. P. Kennedy performed necropsy on the hybrid fetus recovered by Caesarian section. Funds were provided by the USDA W-112 Regional Research Project.

\section{References}

Allen WR (1975) The influence of fetal genotype upon endometrial cup development and PMSG and progestogen production in equids journal of Reproduction and Fertility Supplement 23 405-413

Anderson GB, Bradford GE and Cupps PT (1981) Length of gestation in ewes carrying lambs of two different breeds Theriogenology 16 119-129

Bowerman HRL and Hancock JL (1963) Sheep-goat hybrids Journal of Reproduction and Fertility 6326

Buckrell BC, Gartley CJ, Mehren KG, Crawshaw GJ, Johnson WH, Barker IK, Balke J, Coghill C, Challis JRG and Goodrowe KL (1990) Failure to maintain interspecific pregnancy after transfer of Dall's sheep embryos to domestic ewes Journal of Reproduction and Fertility 90 387-394

Bunch TD, Foote WC and Spillett JJ (1976) Sheep-goat hybrid karyotypes Theriogenology 6 379-386

Butler JE, Hamilton WC, Sasser RG, Ruder CA, Hass GM and Williams RJ (1982) Detection and partial characterization of two bovine pregnancy-specific proteins Biology of Reproduction 26 925-933

Dent J, McGovern PT and Hancock JL (1971) Immunological implications of ultrastructural studies of goat $\times$ sheep hybrid placentae Nature 231 116-117
Dunbar MM, Wong TS, Ruder-Montgomery CA, Chew BP and Sasser RG (1990) Partial characterization of the immunosuppressive properties of pregnancyspecific protein B (PSPB) Theriogenology 33220 (Abstract)

Eckblad WP, Sasser RG, Ruder CA, Panlasigui PM and Kuczynski TS (1985) Localization of pregnancy-specific protein B (PSPB) in bovine placental cells using a glucose oxidase-anti-glucose oxidase immunohistochemical stain Proceedings of the Western Section American Society of Animal Science 36 396-397

Fehilly CB and Willadsen SM (1986) Embryo manipulation in farm animals Oxford Reviews of Reproductive Biology 8 379-413

Gustafson RA, Anderson GB, BonDurant RH and Mahi-Brown C (1993) Tolerance of sheep-goat chimaeras to their component cells Journal of Reproductive Immunology 23 155-168

Hancock JL and McGovern PT (1968) Transfer of goat $\times$ sheep hybrid eggs to sheep and reciprocal transfer of eggs between sheep and goats Research in Veterinary Science 9 411-415

Hancock JL and McGovern PT (1970) Placentae of goat-sheep hybrids Journal of Anatomy 106413 (Abstract)

Hancock JL, McGovern PT and Stamp JT (1968) Failure of gestation of goat $\times$ sheep hybrids in goats and sheep Journal of Reproduction and Fertility Supplement 3 29-36

Humblot P, De Montigny G, Jeanguyot N, Tetedoie F, Payen B, Thibier M and Sasser RG (1990) Pregnancy-specific protein B and progesterone concentrations in French alpine goats throughout gestation journal of Reproduction and Fertility 89 205-212

McGovern PT (1973a) The effect of maternal immunity on the survival of goat $x$ sheep hybrid embryos Joumal of Reproduction and Fertility $\mathbf{3 4}$ 215-220

McGovern PT (1973b) The fate of goat $x$ sheep hybrid embryos in goats treated parenterally with sheep semen Joumal of Reproduction and Fertility $\mathbf{3 4}$ 221-225

MacLaren LA, Anderson GB, BonDurant RH and Edmondson AJ (1992a) Interand intraspecific placentae in sheep, goats and sheep-goat chimaeras Journal of Comparative Pathology 106 279-297

MacLaren LA, Anderson GB, BonDurant RH, Edmondson AJ and Bernoco D (1992b) Maternal serum reactivity to species-specific antigens in sheep-goat interspecific pregnancy Biology of Reproduction 46 1-9

MacLaren LA, Anderson GB, BonDurant RH and Edmondson AJ Reproductive cycles and pregnancy in interspecific sheep-goat chimaeras Reproduction, Fertility and Development (in press)

Moore NW, Halnan CRE, McKee JJ and Watson JI (1981) Studies on hybridization between a Barbary ram (Ammotragus lervia) and domestic ewes (Ovis aries) and nanny goats (Capra hircus) joumal of Reproduction and Fertility 61 $79-82$

Nadler CF, Lay DM and Hassinger JD (1971) Cytogenetic analysis of wild sheep populations in northern Iran Cytogenetics 10 137-152

Reimers TJ, Sasser RG and Ruder CA (1985) Production of pregnancy-specific protein by bovine binucleate trophoblastic cells Proceedings of the Eighteenth Annual Meeting of the Society for the Study of Reproduction Abstract 55

Roth TL, Anderson GB, BonDurant RH and Pashen RL (1989) Survival of sheep $\times$ goat hybrid inner cell masses after injection into ovine embryos Biology of Reproduction 41 675-682

Ruder CA, Stellflug JN, Dahmen JJ and Sasser RG (1988) Detection of pregnancy in sheep by radioimmunoassay of sera for pregnancy-specific protein $B$ Theriogenology 29 905-912

Ruffing NA (1989) Placental Chimerism and its Effect on Interspecies Pregnancy. PhD Thesis, University of California, Davis

SAS (1985) Statistical Analysis Systems (5th Edn). SAS Institute, Inc., Cary, NC

Tucker EM, Denis B and Kilgour L (1989) Blood genetic marker studies of a sheep-goat hybrid and its back-cross offspring Animal Genetics 20 179-186

Warwick BL and Berry RO (1949) Inter-generic and intra-specific embryo transfers in sheep and goats Journal of Heredity $\mathbf{4 0} 297-303$

Whitten WK and Biggers JD (1968) Complete culture of the preimplantation stages of the mouse in vitro Journal of Reproduction and Fertility 17 399-401

Willard JM (1991) Detection of Fetal Twins using a Specific Radioimmunoassay for Pregnancy-Specific Protein B. MS Thesis, University of Idaho

Willard JM, Ruder CA and Sasser RG (1987) Ovine pregnancy-specific protein B concentrations in the sera of early pregnant and peripartum ewes Proceedings of the Western Section of the American Society of Animal Science 38 231-233

Wood AK, Darling A, Dusek GL, Sasser RG and Ruder CA (1986) Serum assay for detecting pregnancy in mule and white tailed deer Journal of Wildlife Management 50 684-687 